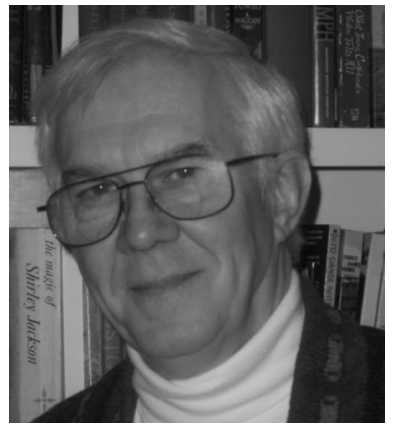

\section{Page Charges}

One of the benefits of my retirement is that I have some time to contemplate things that went unnoticed before. At lunch, for example, I pick the latest issue of oe magazine, Optics and Photonics News, Physics Today, or Photonics Spectra and read as long as I am munching. When I was teaching I rarely had the time and opportunity to read anything beyond the research literature in ultrafast optics.

Also, just before I retired we began to use a different manuscript submission and handling system, Peer X-Press (PXP) from the American Institute of Physics. This system permits all manuscripts to be submitted, assigned, and reviewed using a Web-based browser interface. Authors, Associate Editors, reviewers, SPIE staff, and the Editor enter through the same Web portal (http://oe.peerx-press.org/). However, the number of links that you will see after you sign in depends on the number of roles you have within this publishing universe.

When I open my page I am greeted with a tabular listing of submitted papers. Clicking on a paper shows a series of items including the author, the collaborators, and the abstract. One other item, at the very bottom of the page, that I never had access to before PXP is a statement of the ability of the author to honor page charges for the publication of the paper, if it is accepted. There are three options that the corresponding author may check. Briefly, they are "Yes," "Yes, but only part of the charges," and "No." Although this information has been available since May when we started using PXP for this journal, it was only since retirement that I began to pay attention to the responses in this line. I have not kept any statistics, but my impression is that most authors indicate that they will honor the page charges; but some will not. In some instances, it was obvious that these were researchers with limited resources who hardly had sufficient funds to carry out the experiments.

Another change that PXP brought was the ability to see an entire paper. Previously, the SPIE staff would attach a scan of the first two or three pages to an e-mail. I would open the scanned pages to check to see if the English is good enough for the Associate Editor and the reviewers to be able to evaluate the paper. But, now I have the time and the inclination to open the pdf file to see if the language in the body of the paper is comparable to that in the abstract. But what I noticed when I opened some papers was that the authors declined to honor page charges yet were funded by some agency or institute. Although these papers contained acknowledgments to the agencies that had funded their work, the corresponding authors indicated that they would not honor the page charges. In one case, the authors were employed by a top research university and had three government grants from well-heeled funding sources. I sent an e-mail asking how it was that they could not provide for publication charges. The response was simply that the money had run out.

In another case, when I asked a group of funded researchers why they were unable to honor the page charges, I was told that "...our joint project does not allow us to pay for page charges or other publication cost. I do need to get this paper published in a good journal to meet our deliverables to the funding agency." Another author indicated that their funding source did not allow their funds to be used to pay to publish the results of the work that they paid for!

Off and on, one hears comments that page charges are nothing more than a form of vanity publication for researchers. In contrast to commercial publication, wherein publishers select material that will sell and compensate both them and their authors, vanity publications charge authors to publish their work. One big distinction between research publication and vanity publication is peer-review. No matter how much money one might pay, the publication is dependent on an independent, usually anonymous, constructively critical assessment of the value of the work described in a paper. The other distinction is that, if the work is good, it will be published even if the page charges are not paid.

If that is the case, why should authors pay page charges? The answer is that the payment of $\$ 90$ per page for publication is a professional obligation. These page charges allow SPIE to keep its journal subscription prices low and provide its journals to a large audience. To some degree every paper in this journal is subsidized by SPIE. Those who do not honor page charges, shift more of the burden onto those who do pay and onto SPIE members. 
Almost all grant proposals have a line item in the budget that lists the costs of paying for publication of research. In the case of a US National Science Foundation grant it is:

Publication/Documentation/Dissemination (Line G2 on the Proposal Budget) The proposal budget may request funds for the costs of documenting, preparing, publishing or otherwise making available to others the findings and products of the work conducted under the grant. This generally includes the following types of activities: reports, reprints, page charges or other journal costs (except costs for prior or early publication)....

NSF Grant Proposal Guide (GPG) (NSF 04-23)
Some researchers may treat this item in their budget as a sort of slush fund where they can park money without having to account for its use. Who checks to see if authors have paid their page charges? I would encourage authors to consider why there is a page charge provision in the budget for a grant in the first place. They should use those funds to support society journals that rely on page charges to help defray some of the publication cost and thus keep journal prices at a reasonable level.

Other agencies have similar budget items.

Donald C. O'Shea

Editor 